\title{
Mobile Applications Get Real
}

F irst off, full disclosure: I don't own a PDA. I've long dismissed them as expensive gadgets whose main function is to distract people from the boredom of commuting (not that there's anything wrong with that-my Discman serves quite well in that department). But one need not look far to see the error in my observation. How shocked I was to discover that some of my fellow commuters are doing actual work on their PDAs! And I don't mean just e-mail. A growing number of workers employ these devices to access company data using custom applications developed in-house and then deployed to the field. That's part of what prompted this month's special report on "going mobile." Specifically, we wanted to explore with you the issues that developers and architects face when they set out to build these applications.

Bruce Zenel and Andrew Toy, both from Morgan Stanley, kick off this month's special report by tackling that very topic. "Enterprise-Grade Wireless" (page 30) provides an insider's view of things to think about when your company decides to step up its wireless strategy. Most large companies give their staff PDAs to increase productivity via mobile e-mail access. But what if your company wants to take things a step further and provide mobile access to valuable company data? (Which is not to say that e-mail itself can't be considered "valuable," but I digress.) This is where things quickly get a lot more complex, and Zenel and Toy do a fine job outlining some major areas of concern.

While the development of robust, secure mobile applications for the enterprise is still in its infancy, the market for consumer-based mobile apps is really starting to take off. Accordingly, we wanted to give this area its due. And then some! We've included two features that explore this fun and exciting application space. To all of you command-line junkies: don't dismiss this stuff as "fluff" - there's some interesting technology here.

Queue was lucky enough to enlist a senior director at HP Labs, Fred Kitson, to help cover this part of the mobile applications spectrum. "Making Mobile Media a Reality" (page 38) explores the challenges in developing mobile media apps by way of two prototype applications, each of which presents unique development difficulties. His

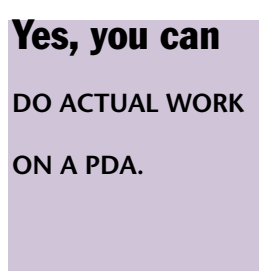

account of developing a mobile multiplayer gaming platform alone is worth your time.

Ever watched TV on your cellphone? Well, you will soon. Tom Gerstel from Turner Broadcasting System shares his insight and expertise on providing mobile video to the masses in "Streams and Standards: Delivering Mobile Video" (page 48). In this article, Gerstel examines the various parts of the mobile video equation, from the codecs and formats to the inherent difficulties in testing these services, given the enormous number of device models.

If you can pull yourself away from watching $\mathrm{CNN}$ on your cellphone, you'll find that this issue offers a lot of interesting and useful information. Queue readers may recall that a few months back we mentioned our interest in exploring "bit dripping," or delivering new functionality to applications in small, managed increments. Well, we found the perfect person to help us in Sun CTO and Distinguished Engineer Tim Marsland (page 20). In this month's interview, Marsland discusses his experience at Sun working on the Solaris operating system and, specifically, how Sun approaches delivering new functionality to Solaris at ever-increasing rates (whilst not breaking the recipient).

This month's features conclude with a real treat. Continuing Queue's "You Don't Know Jack" series, Kevin Fall from Intel and Steve McAnne from Riverbed tackle network performance (page 54). Think it's mostly a bandwidth issue? Think again. There's some great take-away here, so don't let this article go unread.

On the shorter (but not necessarily lighter) side, Queue presents its usual cast of department personalities. Be sure to witness Kode Vicious's showdown with Mothra (random, we know) and Phil Laplante's enlightening and entertaining field guide to "Mal Managerium," or bad IT managers—not that any of us fit that category. Happy reading! $Q$

JOHN STANIK is associate managing editor for ACM Queue. $\mathrm{He}$ is now seriously considering buying a PDA. 